\title{
Interrelationship between lung volume, expiratory flow, and lung transfer factor in fibrosing alveolitis
}

\author{
JN PANDE \\ From the Respiratory Laboratory, All India Institute of Medical Sciences, Ansari Nagar, New Delhi, India
}

ABSTRACT Fifty patients with fibrosing alveolitis studied on 104 occasions exhibited significant direct correlations between vital capacity (VC), maximum mid-expiratory flow rate (MMFR), and transfer factor for carbon monoxide (TLCO). Forced expired volume in the first second (FEV 1 )/VC ratio bore a weak negative correlation with VC. Peak expiratory flow, MMFR, and maximum flow rates at $50 \%$ and $25 \%$ of $\mathrm{VC}$ were often reduced in patients with severe grades of pulmonary dysfunction. It appears that as the severity of the fibrotic process increases, the lung volumes shrink and the transfer factor for $\mathrm{CO}$ decreases. The total lung capacity decreases predominantly on account of reduction in VC. With a decrease in lung volume the MMFR also falls. Decrease in flow rates at low lung volumes is greater as compared to the fall in peak flow. The expiratory flow rates however were normal or even increased when related to absolute lung volume. Some patients exhibit disproportionate expiratory slowing as evidenced by a decrease in MMFR which is out of proportion to the reduction in VC. These patients also have a reduced $\mathrm{FEV}_{1} / \mathrm{VC}$ ratio. These changes are probably the consequence of associated peripheral airway narrowing.

Increased elastic recoil of the lung limiting maximal inflation is considered to be the main abnormality of lung mechanics in fibrosing alveolitis. Interstitial lung diseases are also characterised by decrease in lung transfer factor. Certain investigators ${ }^{1-3}$ have also described abnormalities of peripheral airways in these patients, whereas others ${ }^{4} 5$ have found airway function to be normal. In most of the reported series the number of patients studied has been small and interrelationships between lung volumes, transfer factor, and expiratory flow rates have not been described. Cryptogenic fibrosing alveolitis is frequently seen in young females in this part of the world and a large majority of these patients are nonsmokers. This communication describes the spectrum of abnormalities found and their interrelationship on simple physiological evaluation in a large group of patients with fibrosing alveolitis of variable severity.

\section{Methods}

Fifty patients with cryptogenic fibrosing alveolitis were referred for evaluation of pulmonary function during the period 1971-78. There were 17 men and

Address for reprint requests: JN Pande, Associate Professor of Medicine, Department of Medicine, All India Institute of Medical Sciences, Ansari Nagar, New Delhi, India.
33 women. Their age ranged from 16-68 years (mean $\pm \mathrm{SE} 42 \cdot 1 \pm 1 \cdot 7$ years). There were seven exsmokers among the men whereas none of the women had ever smoked. The duration of their symptoms ranged from 15 days to 10 years (mean \pm SE $2 \cdot 5 \pm$ $0 \cdot 3$ years). The diagnosis was based on typical clinical findings, radiological evidence of interstitial lung disease, and characteristic functional abnormalities. Patients with extrinsic allergic alveolitis, collagen disorders, sarcoidosis, or other known causes of interstitial lung disease were excluded from the analysis after appropriate investigation. None of these patients had lung biopsy for histopathological confirmation of the diagnosis. The 50 patients had routine functional evaluation on 104 occasions. They were followed up for periods ranging from one month to eight years (mean 15.4 months). Sixteen patients were lost to follow-up soon after initial evaluation, 12 died during the period of follow-up, and 22 were still alive with varying grades of disability at the end of 1978 . None of those who died came to necropsy.

The parameters of pulmonary function analysed in this report include slow vital capacity (VC), $\mathrm{FEV}_{1}$ / VC ratio, maximum mid-expiratory flow rate (MMFR), and lung transfer factor for CO (TLCO). Slow VC was recorded on 13.5 1 Collins spirometer. FEV $_{1}$ and MMFR were calculated from a fast speed 
Table 1 Results of routine pulmonary function tests (mean $\pm S E)$ in 50 patients with fibrosing alveolitis

\begin{tabular}{|c|c|c|c|c|c|}
\hline $\begin{array}{l}\text { TLCo range } \\
(\% \text { predicted })\end{array}$ & $\begin{array}{l}\text { Number of } \\
\text { observations }\end{array}$ & $\begin{array}{l}\text { TLCO } \\
\text { (\% predicted) }\end{array}$ & $\begin{array}{l}V C \\
(\% \text { predicted })\end{array}$ & $\begin{array}{l}F E V_{1} \\
(\% V C)\end{array}$ & $\begin{array}{l}\text { MMFR } \\
(\% \text { predicted })\end{array}$ \\
\hline $\begin{array}{l}80 \text { and above } \\
60-79 \\
40-59 \\
30-39 \\
<30\end{array}$ & $\begin{array}{r}6 \\
16 \\
30 \\
25 \\
27\end{array}$ & $\begin{array}{l}87.8 \pm 2.2 \\
68.5 \pm 1.7 \\
48.4 \pm 1.0 \\
34.5 \pm 0.6 \\
23.9 \pm 0.8\end{array}$ & $\begin{array}{l}60.7 \pm 4 \cdot 6 \\
57 \cdot 3 \pm 3 \cdot 2 \\
52 \cdot 6 \pm 2 \cdot 3 \\
46 \cdot 0 \pm 2 \cdot 5 \\
35.7 \pm 2 \cdot 1\end{array}$ & $\begin{array}{l}84 \cdot 7 \pm 4 \cdot 1 \\
84 \cdot 4 \pm 3 \cdot 2 \\
85 \cdot 3 \pm 1 \cdot 7 \\
88 \cdot 0 \pm 1 \cdot 8 \\
87 \cdot 2 \pm 2 \cdot 2\end{array}$ & $\begin{array}{l}89 \cdot 8 \pm 19 \cdot 1 \\
77 \cdot 2 \pm 9 \cdot 4 \\
69 \cdot 1 \pm 6 \cdot 3 \\
62 \cdot 2 \pm 6 \cdot 2 \\
45 \cdot 1 \pm 4 \cdot 0\end{array}$ \\
\hline
\end{tabular}

expirogram recorded with a low resistance spirometer. TLCo was measured by the steady state technique of Bates et $\mathbf{l}^{6}$ using a Rahn and Otis end-tidal sampler for obtaining alveolar air. All the results were recorded for BTPS conditions and expressed as per cent of the predicted values using the regression formulae of Goldman and Becklake ${ }^{7}$ and Bates et al. ${ }^{8}$ These prediction formulae have been found to be satisfactory for use in North Indian subjects studied in Delhi. ${ }^{910}$ In 13 patients (three men and 10 women), airway resistance (Raw), and thoracic gas volume during panting were measured using a constant volume body plethysmograph according to the method of DuBois et al. ${ }^{11}$ With each subject seated outside the box maximum expiratory flowvolume curves were also obtained using a dry wedge spirometer (Med-Science, USA). Thus the volume of the gas exhaled from the mouth was recorded against instantaneous flow. Each maximal expiratory manoeuvre was preceded by two slow and deep inspirations in order to standardise the volume history. Flow-volume curves were recorded in triplicate and those with the largest VC were used for the final analysis. From the flow-volume curves the peak flow and the maximum flow rates after exhalation of $50 \%$ and $75 \%$ of $\mathrm{VC}\left(\dot{\mathrm{V}}_{50}\right.$ and $\dot{\mathrm{V}}_{25}$ respectively) were read off. They were compared with the predicted values for the given age, sex, and height according to the regression equation of Cherniack and Raber. ${ }^{12}$ Standard statistical methods were used for the calculation of coefficients of regression for pairs of parameters.

\section{Results}

Using the degree of reduction in Thco as an index of the severity of fibrosing alveolitis, the results of pulmonary function testing have been graded into five groups as shown in table 1 . Repeat tests in the same subject have been treated as independent observations. There was a progressive decline in VC and MMFR as TLCo decreased. FEV 1 /VC ratio was higher than normal at all grades of dysfunction. MMFR was greater than predicted in only 19 of the 104 observations. Vital capacity was frequently reduced even at early stages of the disease when TLCO was still within normal limits.
Table 2 Coefficients of correlation between vital capacity, FEV, MMFR, and TLCO based on 104 observations in 50 patients with fibrosing alveolitis

\begin{tabular}{lcclc}
\hline & $V C$ & $\begin{array}{l}F E V_{1} \\
(\% V C)\end{array}$ & $M M F R$ & $T$ LCO \\
\hline VC & 1.00 & $-0.23^{*}$ & $0.43^{* * *}$ & $0.54^{* * *}$ \\
FEV & 1.00 & $0.59^{* * *}$ & -0.09 \\
MMFR & & & 1.00 & $0.40^{* * *}$ \\
\hline
\end{tabular}

$* p<0.05$

$* * * p<0.001$

The coefficients of correlation between various functional parameters have been given in table 2 . VC, TLCo, and MMFR bore significant direct correlations among themselves. The $F E V_{1} / V C$ ratio exhibited a poor but statistically significant negative correlation with VC and a highly significant positive correlation with MMFR. The coefficient of partial correlation between $\mathrm{VC}$ and $\mathrm{FEV}_{1} / \mathrm{VC}$ after excluding the effect of MMFR improved to -0.67 ( $p<$ 0.001 ). The relationship between MMFR and VC is illustrated in fig 1 . Most of the time the decrease in MMFR was less striking than the corresponding change in VC except on 34 occasions when the reverse was observed. When the MMFR was disproportionately reduced, the $\mathrm{FEV}_{1} / \mathrm{VC}$ ratio also was usually low (fig 1).

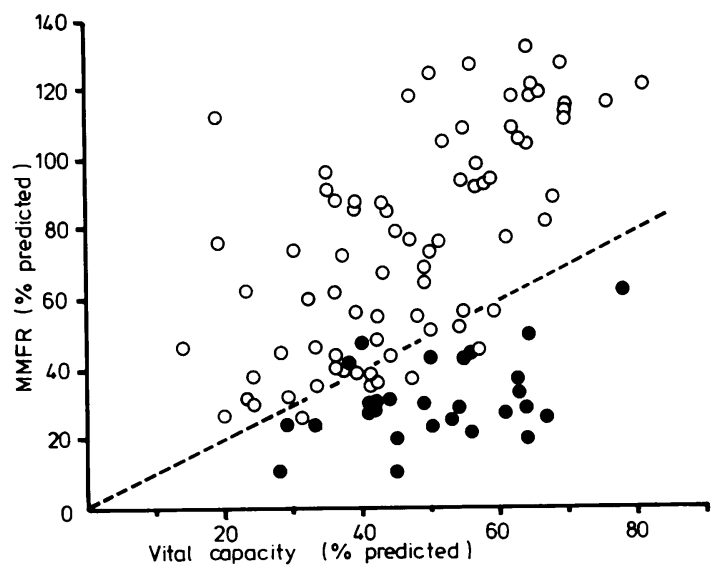

Fig 1 Correlation between vital capacity and maximum mid-expiratory flow rate. Interrupted line is the line of identity. $\bigcirc F E V_{1} / V C>80 \% ; \bigcirc F E V_{1} / V C<80 \%$. 
Table 3 Specific conductance, total lung capacity, peak expiratory flow, and maximum flow rates at $50 \%$ and $25 \%$ of vital capacity in 13 patients with fibrosing alveolitis

\begin{tabular}{|c|c|c|c|}
\hline Parameters & Predicted Mean $\pm S E^{*}$ & Observed Mean $\pm S E$ & $\%$ Predicted Mean $\pm S E$ \\
\hline $\begin{array}{l}\text { TLCO }\left(\mathrm{m} \mathrm{mol} \mathrm{min} \mathrm{mi} \mathrm{Pa}^{-1}\right) \\
\text { TLC (1) } \\
\text { VC (1) } \\
\text { MMFR }\left(1 \mathrm{~s}^{-1}\right) \\
\text { Raw }\left(\mathrm{k} \mathrm{Pa} \mathrm{1}^{-1} \mathrm{~s}\right) \\
\text { sGaw }\left(\mathrm{s}^{-1} \mathrm{k} \mathrm{Pa}^{-1}\right) \\
\text { Peak flow }\left(1 \mathrm{~s}^{-1}\right) \\
\dot{\mathrm{V}}_{\text {so }}\left(1 \mathrm{~s}^{-1}\right) \\
\dot{\mathrm{V}}_{25}\left(1 \mathrm{~s}^{-1}\right)\end{array}$ & $\begin{array}{l}5.56 \pm 0.26 \\
4.44 \pm 0.23 \\
2.99 \pm 0.14 \\
3 \cdot 13 \pm 0.12 \\
0.10-0.25 \\
1 \cdot 5-4.0 \\
6.50 \pm 0.33 \\
4.47 \pm 0.15 \\
2.33 \pm 0.12\end{array}$ & $\begin{array}{l}2.54 \pm 0.32 \\
2.94 \pm 0.32 \\
1.57 \pm 0.14 \\
2 \cdot 22 \pm 0.24 \\
0.20 \pm 0.03 \\
2 \cdot 59 \pm 0.50 \\
5.23 \pm 0.57 \\
2.68 \pm 0.49 \\
1.19 \pm 0.23\end{array}$ & $\begin{array}{l}47 \cdot 6 \pm 6 \cdot 0 \\
68 \cdot 1 \pm 6 \cdot 9 \\
53 \cdot 1 \pm 4 \cdot 4 \\
72 \cdot 2 \pm 8 \cdot 0 \\
\\
80 \cdot 4 \pm 8 \cdot 2 \\
61 \cdot 1 \pm 11 \cdot 3 \\
54 \cdot 6 \pm 11 \cdot 6\end{array}$ \\
\hline
\end{tabular}

*Except for Raw and sGaw where the normal range in the laboratory is indicated.

For conversion into traditional units of TLCO $\left(\mathrm{ml} \mathrm{min}^{-1}\right.$ torr-1), Raw $\left(\mathrm{cm} \mathrm{H}_{2} \mathrm{O} \mathrm{l}^{-1} \mathrm{~s}\right)$ or sGaw $\left(\mathrm{s}^{-1} \mathrm{~cm} \mathrm{H}_{2} \mathrm{O}^{-1}\right)$ multiply the values given in the table by $2 \cdot 99,10 \cdot 0$, or $0 \cdot 1$ respectively.

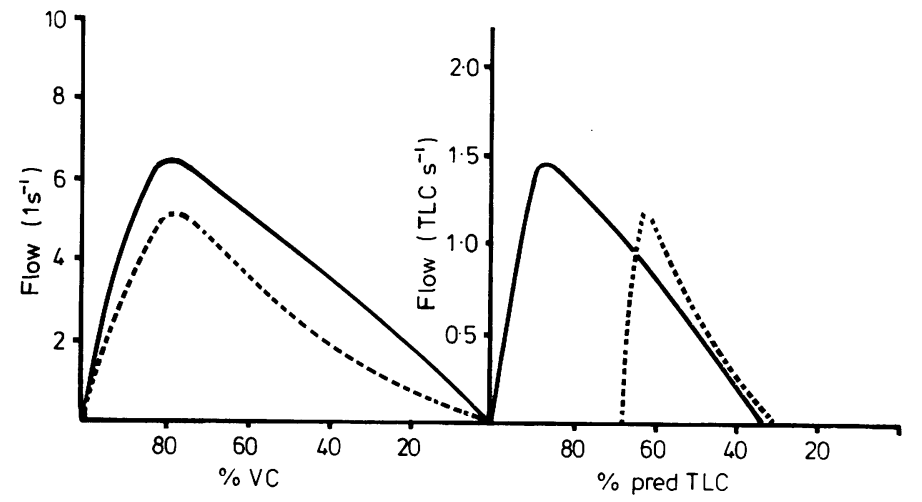

Fig 2 Flow-volume curves (interrupted lines) in 13 subjects with fibrosing alveolitis. Normal curves for these subjects (continuous lines) are based on the data of Cherniack and Raber ${ }^{12}$.

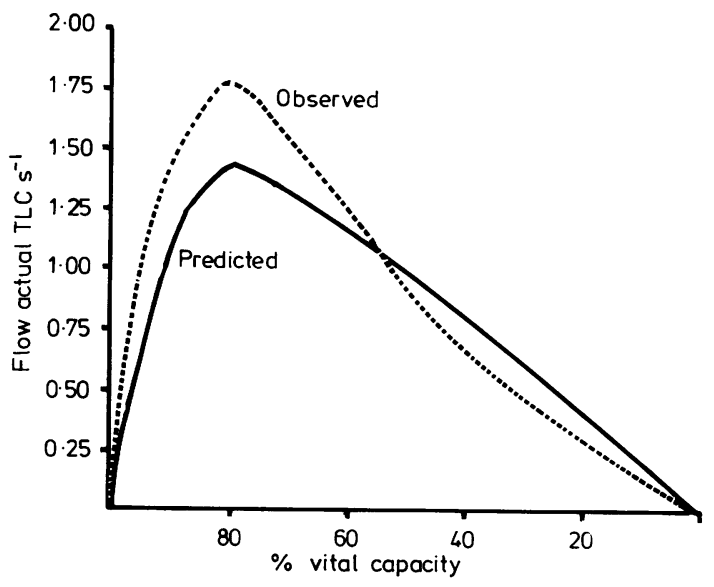

Fig 3 Flow-volume curves in 13 subjects with fibrosing alveolitis. - - - observed.

Table 3 gives the values for specific conductance (sGaw), total lung capacity (TLC), $\dot{\mathrm{V}}_{50}$, and $\dot{\mathrm{V}}_{25}$ in a group of 13 subjects in whom these parameters were studied. Predicted values 10 in normal subjects of similar age, sex, and height are also shown. The specific conductance was normal although Raw was $\overrightarrow{\vec{\partial}}$ increased in three subjects and decreased in one subject. TLC was significantly less than the predicted value. The peak flow rate, MMFR, $\dot{V}_{50}$, and $\dot{V}_{25}$ 을 were also significantly lower than predicted. The decrease in flow rates at low lung volumes was more striking than that seen at large lung volumes. Flowvolume curves incorporating the observed and predicted mean values of peak flow, $\dot{\mathbf{V}}_{50}$, and $\dot{V}_{25}$ have been represented schematically in figs 2 and 3 .

\section{Discussion}

This series of patients with cryptogenic fibrosing $\frac{7}{3}$ alveolitis differs from others reported in the literature in that our patients were younger (mean age $42 \%$ years) and often female $(66 \%)$. On account of female $N$ preponderance, only seven (all men) of the 50 sub- ్ㅓ jects had been ex-smokers since smoking by women is not generally socially acceptable. Moreover the

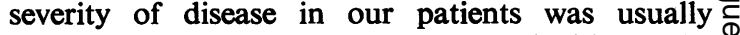
greater. Twelve of the patients $(24 \%)$ died in respir- $\stackrel{\mathcal{D}}{?}$ atory failure after an average duration of 20 months $T$ follow-up. Although the diagnosis was not substan- $\overline{0}$ tiated histopathologically, all the patients reported $\overparen{\otimes}$ in this series had clinical, physiological and radio- $\mathbb{D}$ logical abnormalities consistent with cryptogenic 
fibrosing alveolitis. All the patients, particularly young females, were screened for collagen disorders but none was found. Antinuclear factor was positive in low titres in seven patients but there were no other features of systemic disease. None of the patients was occupationally exposed to birds. In four patients there was a history of contact with birds (pigeons two, fowls two) but their sera were negative for precipitins against appropriate antigens. Kveim tests performed in six subjects because of a suspicion of hilar lymphadenopathy were negative and none of the other features of sarcoidosis were present. A close scrutiny of the home environment and the place of work failed to reveal any likely cause of hypersensitivity pneumonitis. It is possible however that some of the patients had a form of extrinsic allergic alveolitis produced by an unsuspected antigen. The patterns of functional abnormality in fibrosing alveolitis of the "extrinsic" or "cryptogenic" varieties are not very different and several investigators have studied a mixed group of subjects. ${ }^{5}$

The findings of low VC, TLC, and TLCo with increased $\mathrm{FEV}_{1} / \mathrm{VC}$ are characteristic of interstitial lung disease. The frequency with which low flow rates (peak flow, MMFR, $\dot{\mathrm{V}}_{50}$, and $\dot{\mathrm{V}}_{25}$ ) were encountered in the present series of patients has not been reported earlier. Flow limitation in fibrosing alveolitis could be a consequence of certain regions of the lung being entirely non-functional so that the corresponding airways do not have any airflow. It could also be a manifestation of anatomical airway narrowing because of peribronchial fibrosis and distortion. Flow rates at different absolute lung volumes however may be increased on account of the increased elastic recoil of the lung providing a higher driving pressure. An interplay of these factors makes the assessment of airway function with the help of flow volume curves difficult. Different authors have presented flow volume curves in different ways. Thus Gibson and Pride ${ }^{4}$ expressed flow rates as predicted TLC s ${ }^{-1}$ in order to correct the observed flow rates for difference in body size but not actual lung size. They found the peak flow rate and $\dot{\mathrm{V}}_{50}$ and $\dot{\mathrm{V}}_{25}$ to be increased or within normal limits in eight patients with fibrosing alveolitis. The expiratory flow rates were particularly excessive when related to the absolute lung volume, rather than per cent of vital capacity expired. The findings of the present study indicate a reduction in absolute flow rates when related to per cent of vital capacity expired (fig 2). Similar observations have been reported by other workers. ${ }^{13}$ The same flow rates, however, appear excessive or normal when related to absolute lung volume (fig 2). These differences in findings appear to be attributable to greater severity of fibrosis in the present series of patients. Thus the mean VC in 3 *
Gibson and Pride's series of patients was higher (65\% predicted) than that in the group of patients with the mildest form of disease in the present series (see table 1). These authors presented an analysis of flow-volume relationships as visualised in a shrunken lung model (where all the alveoli are uniformly stiff) or a small lung model (where patchy areas of the lung parenchyma and the corresponding airways are entirely non-functional). In the former situation no decrease in MMFR, peak flow, $\dot{V}_{50}$, or $\dot{V}_{25}$ is anticipated. In the small lung model however, all these flow rates must fall in proportion to decrease in lung volumes. It appears, therefore, that a large majority of patients in the present series had a reduced number of ventilated alveoli.

Fulmer et $a l^{1}$ expressed expiratory flow rates as actual TLC s${ }^{-1}$ and related them to the per cent of VC expired. This would be a useful method of studying airway function in a small lung model. In half of their patients $\dot{V}_{50}$ and $\dot{V}_{25}$ were found to be reduced. The authors observed a significant correlation between reduced expiratory flow rates and morphological evidence of peripheral airway narrowing. When expressed in this fashion, expiratory flow' rates in the present series of patients were rather similar to the findings of Fulmer et al (fig 3). It is possible, therefore, that with advancing severity of fibrosis, narrowing of the peripheral airways also contributes towards reduced flow rates. This is in accordance with observations on upstream conductance which has been variously reported as normal ${ }^{4} 5$ or reduced ${ }^{1-31415}$ in patients with interstitial lung diseases. It must be emphasised, however, that the abnormalities of the expiratory flow-volume relationship observed in this study could alternatively be explained by marked differences in regional compliance in a small lung. A correlation between reduced flow rates at low lung volumes, frequency dependence of dynamic compliance, and morphological estimation of the peripheral airway diameter has been demonstrated. ${ }^{1}$ In view of this it is possible that some of the patients in the present series also had peripheral airway narrowing.

None of the reported series have analysed interrelationships between lung volume, flow rates, and transfer factor in fibrosing alveolitis. We observed a direct correlation between VC and TLCo in these patients. Both of these parameters may be used to assess the severity of the disease and for follow-up of the patients. With advancing severity of the disease however, TLCo declined much more rapidly than VC (table 1). This may have occurred because a thickening of the alveolar-capillary membrane not only increases the diffusion barrier for $\mathrm{CO}$, but also reduces the alveolar volume upon which measured TLCO is also dependent. Moreover, greater ventila- 
tion-perfusion abnormalities with increasing severity of fibrosis would also affect TLCO, particularly when measured by the steady state method. Thus patients with advanced disease have an additional cause for reduced TLCO. In this study MMFR correlated significantly with TLCO. The coefficient of partial correlation between MMFR and TLCo after eliminating the effect of $\mathrm{VC}$ was still significant $(\mathrm{r}=$ $0.022 ; p<0.05$ ) indicating that low flow rates contributed towards reduced TLCo. This was presumably the consequence of peripheral airway disease aggravating the $\dot{V} / \mathbf{Q}$ abnormalities. The data of Fulmer et $a l^{1}$ show a lack of correlation between TLCo (single breath) and VC. This may be because of a small number of observations and patients, half of whom had evidence of peripheral airway disease.

The relationship between VC and MMFR is illustrated in fig 1 . There was a significant correlation between the two $(p<0.001)$ with most subjects having a greater reduction in $\mathrm{VC}$ as compared to MMFR. There was a group of observations, however, where the reduction in MMFR was out of proportion to the decrease in VC. Similar observations have been reported by Levinson et $a^{14}$ in a group of patients with sarcoidosis. Theoretically both shrunken and small lung models of Gibson and Pride $^{4}$ should be associated with high or normal MMFR when related to VC. Although most of our observations are consistent with this concept, disproportionate expiratory slowing was observed 34 times, out of which the FEV $/$ VC was less than $80 \%$ on 26 occasions, whereas this finding was present in only two of the remaining 70 observations (fig 1). This emphasises the relationship between MMFR/ $\mathrm{VC}$ and $\mathrm{FEV}_{1} / \mathrm{VC}$ reported by Kuperman and Riker. ${ }^{16}$

It is interesting that although MMFR bore a significant positive correlation with both $\mathrm{VC}$ and $F E V_{1}$, the last two were inversely correlated between themselves. This is because $\mathrm{FEV}_{1}$ (expressed as \%VC) is a ratio dependent upon which of the two parameters (vital capacity or expiratory flow rate) are more severely reduced. In agreement with earlier observations, ${ }^{45}$ it was normal or increased in spite of reduced expiratory flow rates. It was reduced in some patients with disproportionate expiratory slowing; a finding which has also been reported earlier. ${ }^{2} 1415$ It is possible that patients with low $\mathrm{FEV}_{1}$ also had significant peripheral airway narrowing.

\section{References}

1 Fulmer JD, Roberts WC, von Gal ER, Crystal RG. Small airways in idiopathic pulmonary fibrosis. Comparison of morphologic and physiologic observations. $J$ Clin Invest 1977;60:595-610.

${ }^{2}$ Ostrow D, Cherniack RM. Resistance to airflow in patients with diffuse interstitial lung disease. Am Rev Respir Dis 1973;108:205-10.

${ }^{3}$ Warren CPW, Tse KS, Cherniack RM. Mechanica properties of the lung in extrinsic allergic alveolitis. Thorax 1978;33:315-21.

4 Gibson GJ, Pride NB. Pulmonary mechanics in fibrosing alveolitis. The effect of lung shrinkage. Am Rev Respir Dis 1977;116:637-47.

${ }^{5}$ Schofield NMc, Davies RJ, Cameron IR, Green M. Small airways in fibrosing alveolitis. Am Rev Respir Dis 1976; 113:729-35.

6 Bates DV, Boucot NG, Dormer AE. Pulmonary diffusing capacity in normal subjects. $J$ Physiol (London) 1955; 129:237-52.

7 Goldman HI, Becklake MR. Respiratory function tests normal values at median altitudes and the prediction of normal results. Am Rev Tuberc 1959;79:457-67.

${ }^{8}$ Bates DV, Woolf CR, Paul GI. Chronic bronchitis: a report on the first two stages of the co-ordinated study of chronic bronchitis in the Department of Veterans Affairs. Med Serv J Canada 1962;18: no4.

9 Jain SK, Ramiah, TJ. Normal standards of pulmonary function tests for healthy Indian men 15-40 years old. Comparison of different regression equations. Indian $J$ Med Res 1963;57:1453-66.

${ }^{10}$ Guleria JS, Sharma MP, Pande JN, Ramchandran K Pulmonary diffusing capacity in normal Indian subjects. Indian J Physiol Pharmacol 1970;14:245-51.

${ }^{11}$ DuBois AB, Botelho SY, Comroe JH Jr. A new method for measuring airway resistance in man using a body plethysmograph. Values in normal subjects and in patients with respiratory disease. J Clin Invest 1956;35: 327-35.

12 Cherniack RM, Raber MB. Normal standards for ventilatory function using an automated wedge spirometer. Am Rev Respir Dis 1972;106:38-46.

${ }^{13}$ Jayamanne DS, Epstein H, Goldring RM. The influence of lung volume on expiratory flow rates in diffuse interstitial lung disease. Am J Med Sci 1978;275:329-36.

14 Levinson RS, Metzger LF, Stanley NN et al. Airway function in sarcoidosis. Am J Med 1977;62:51-9.

${ }^{15}$ Allen DH, Williams GV, Woolcock AJ. Bird breeders hypersensitivity pneumonitis: progress studies of lung function after cessation of exposure to provoking antigen. Am Rev Respir Dis 1976;114:555-66.

16 Kuperman AS, Riker JB. The predicted normal maximal mid-expiratory flow. Am Rev Respir Dis 1973;107: 231-8. 